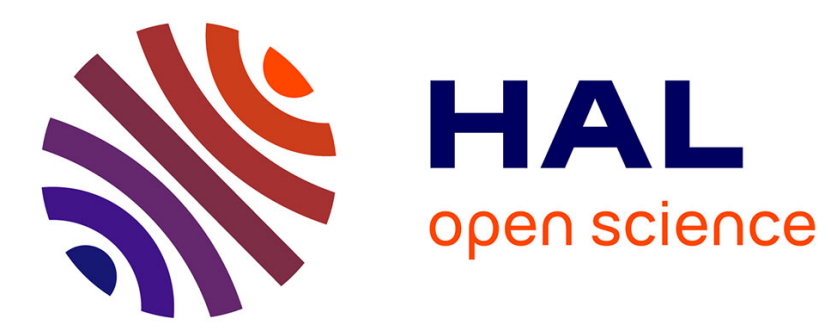

\title{
Supervision of autonomous vehicles: mutual modeling and interaction management
}

Gilles Coppin, François Legras, Sylvie Saget

\section{To cite this version:}

Gilles Coppin, François Legras, Sylvie Saget. Supervision of autonomous vehicles: mutual modeling and interaction management. HCI International: 13th International Conference on Human-Computer Interaction, Jun 2009, Diego, Ca, United States. pp.489 - 497. hal-01215138

\author{
HAL Id: hal-01215138 \\ https://hal.science/hal-01215138
}

Submitted on 13 Oct 2015

HAL is a multi-disciplinary open access archive for the deposit and dissemination of scientific research documents, whether they are published or not. The documents may come from teaching and research institutions in France or abroad, or from public or private research centers.
L'archive ouverte pluridisciplinaire HAL, est destinée au dépôt et à la diffusion de documents scientifiques de niveau recherche, publiés ou non, émanant des établissements d'enseignement et de recherche français ou étrangers, des laboratoires publics ou privés. 


\title{
Supervision of Autonomous Vehicles: Mutual Modeling and Interaction Management
}

\author{
Gilles Coppin $^{1,2}$, François Legras ${ }^{1,2}$ and Sylvie Saget ${ }^{1,2}$ \\ ${ }^{1}$ Institut Télécom; Télécom Bretagne; UMR CNRS 3192 Lab-STICC \\ ${ }^{2}$ Université européenne de Bretagne \\ \{gilles.coppin, francois.legras, sylvie.saget\}@telecom-bretagne.eu
}

\begin{abstract}
As the capabilities of Unmanned Vehicle Systems increase, the tasks of their operators become more and more complex and diverse. Accordingly, the interfaces of these UVSs must become smarter in order to support these tasks and assist the operator. In this paper, we discuss how an Operator Support System can leverage dynamic interaction strategies to modulate the workload of the operator and how it could impact trust in automation.

Keywords: unmanned vehicles systems, interaction, dialogue, trust in automation.
\end{abstract}

\section{Introduction}

Unmanned Vehicle Systems (UVSs) will considerably evolve within the next two decades. In the current generation of UV Systems, several ground operators operate a single vehicle with limited autonomous capabilities, whereas, in the next generation of UV Systems, a ground operator will have to supervise a system of several cooperating vehicles performing a joint mission, i.e. a Multi-Agent System (MAS) $[2,3]$. In order to enable mission control, the autonomy of the vehicle and of the system will increase and will require new and richer forms of Human-system interaction.

The operator of an UVS performs two tasks at the same time: (1) mission command \& control, and (2) interaction with the system. Both tasks induce varying workloads during the system's operation. In current systems, interaction is barely distinguishable from command \& control. But as UVSs evolve, the interaction workload will rise as the operator will have to switch between several vehicles, streams of data, decision support systems, and so on. As Mouloua et al. have pointed out [1], the complexity of the interaction mechanisms between the operators and the system, and the complexity of the mission should vary in opposite ways. If mission complexity goes up (higher workload), interaction complexity should go down (simpler interaction with the system). 
Coppin, G., Legras, F. and Saget, S.

In this perspective, we propose to dynamically leverage different interaction strategies in the context of operator-UVS activities in order to modulate the workload of the operator. In the remainder of this section, we describe the roles of the Operator Support System in these future UVSs and the kind of interaction that they should support. In section 2, we discuss the interaction models that provide a basis for our work. Section 3 exposes our rationale for workload adaptation via dynamic interaction strategies, and section 4 discusses trust in automation and mutual modeling between the operator and the interactive system.

\subsection{Roles of an Operator Support System in future UVSs}

From the perspective of this paper, the main component of the Ground Control Station $^{1}$ (GCS) of an UVS is the Operator Support System (OSS) i.e. the information system that allows the command \& control of the UVS by the operator. The OSS should support the following functions:

- Situation Awareness (SA) and information display, the OSS should make available to the operator all mission-related data i.e. information about vehicles (position, status, etc.), information about mission elements (objectives, threats, maps, etc.), data from vehicles' sensors (e.g. video feed);

- Vehicle command \& control $\left(C^{2}\right)$, the OSS should allow the operator to issue commands to the Vehicles of the system and track their progress;

- Decision support, as UVS operational capabilities increase, the OSS should provide the operator with decisional aids of some sort (e.g. semi-automatic route planning, information fusion).

As a support to these new functions, the OSSs will integrate two additional roles in the UVS:

- Interaction management, considering the wealth of possible two-way interactions at different levels ( $\mathrm{SA}, \mathrm{C}^{2}$, decision support, see section 1.2) between the OSS and the operator, it becomes necessary to regulate these interactions. In similar ways to Human interaction, it becomes necessary to manage turn-taking, interruptions, task priorities and so forth;

- Semantic bridge, as interactions within the UVS become more abstract (higher level) than the current remote operation, some kind of translation service becomes necessary. There is a need to convert operational commands from the operator side to machine-understandable instructions, for instance if

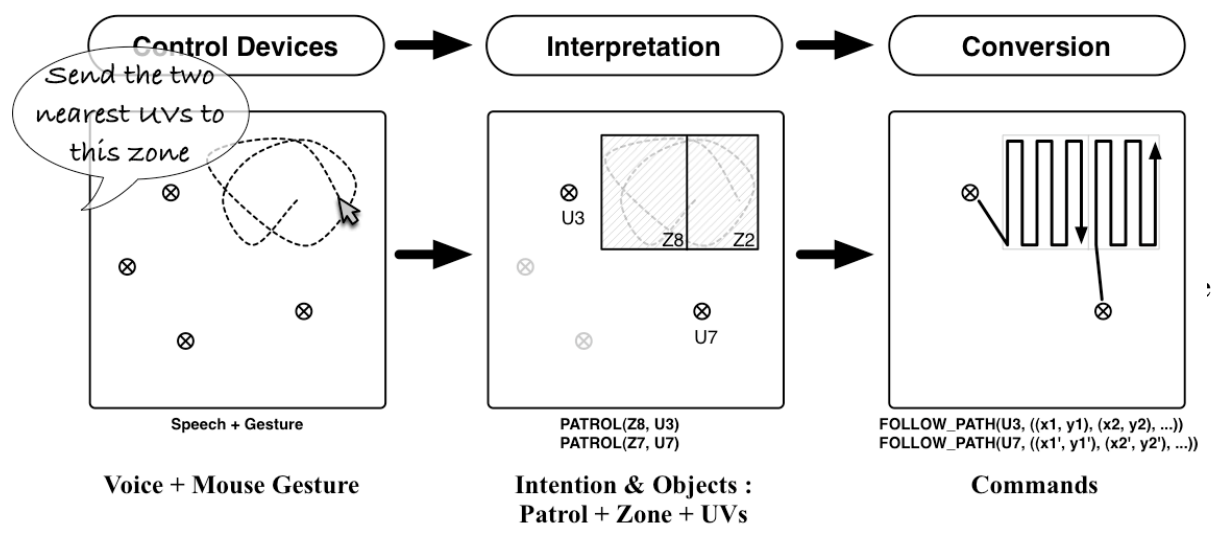

Figure 1. Illustration of the concept of semantic bridge on multi-UV system. 
the operator instructs a system of several vehicles to perform a search on a specific zone (see Figure 1). Similarly, one has to convert multiple sensor data or Decision Support System (DSS) output to Human-understandable form.

\subsection{Types of interaction and non-understandings}

As was stated earlier, several types of interaction can happen between the operator and the OSS. Furthermore, several parts of the UVS can initiate interactions, notably: operator, vehicles and decision support systems. Table 1 illustrates some of these types interaction.

Table 1. Types of interaction.

\begin{tabular}{|l|l|l|}
\hline Initiator $\rightarrow$ addressee & Interaction type & Examples in natural language \\
\hline Operator $\rightarrow$ Vehicles & Command \& Control & $\begin{array}{l}\text { "Send the two nearest Vehicles to patrol } \\
\text { zone 1" }\end{array}$ \\
\hline DSS $\rightarrow$ Operator & Decision support & $\begin{array}{l}\text { "The intruder detected on the north } \\
\text { fence seems headed toward hangar 2" }\end{array}$ \\
\hline Operator $\rightarrow$ OSS & Interaction management & $\begin{array}{l}\text { "Do not disturb me for the next two } \\
\text { minutes" }\end{array}$ \\
\hline Operator $\rightarrow$ OSS & Interface manipulation & $\begin{array}{l}\text { "Display the power lines and zoom on } \\
\text { the alarm" }\end{array}$ \\
\hline
\end{tabular}

Every type of high-level interaction ${ }^{2}$ can produce non-understandings. Humans usually deal with non-understanding by clarifying things. This is also applicable to operator-OSS interactions, with the OSS asking to re-phrase or for some clarification as in the following example:

- Operator: "Send UV2 to the building"

- OSS: "Which building?"

- Operator: "The building near the airport"

- OSS: "North of the airport?"

- Operator: "Yes"

- OSS: "OK."

Here, the feedback "OK" allows the participants to consider the non-understanding to be solved. Although this example is expressed in natural language interaction, a similar exchange could happen via more conventional means, with for example the OSS highlighting the building on the map.

${ }^{2}$ High-level considered as opposed to low-level interaction like clicking on a button. 
Coppin, G., Legras, F. and Saget, S.

\section{Interaction}

\subsection{Interaction as a Collaborative Activity}

The traditional view of interaction [4,5] defines it as a unidirectional process resulting from two individual activities: the generation of a communicative act by the speaker and the understanding and interpretation of this communicative act by the addressee. The success of an interaction is a consequence of the cooperative attitude of the speaker (his sincerity, his relevance, etc.). Consequently, the production of a suitable communicative act is concentrated on a single exchange and a single agent. The complexity (i.e. the cognitive load) of such a process is high. Moreover, the set of possible strategies to produce and understand a communicative act is very limited. The addressee having a passive role, positive feedbacks such as "Okay", "Mhm", "uhuh", nodding, etc., signaling successful understandings, are not necessary. Finally, non-understandings are regarded as communication errors, which have to be handled by additional complex mechanisms.

In contrast with this traditional view, collaborative models define interaction as a bidirectional process resulting from a single social activity [6]. Interaction is considered as a collaborative activity between dialog partners oriented toward the shared goal of reaching mutual understanding. Mutual understanding is reached through negotiation on interpretation, which is a form of interactive refinement of understanding until a sufficient point of intelligibility is reached. Consequently, the production of a suitable communicative act can be distributed between several exchanges from several dialog partners. The effort needed from each partner in such a process is lower than the effort produced by the speaker in the traditional view of interaction i.e. each partner has to contribute in some way to the interaction. The addressee has an active role, explicit and implicit feedbacks are required in order to publicly signal successful understandings. Finally, note that non-understandings are fully expected events in the process of negotiation and part of the model.

\subsection{Interaction as a Subordinate Activity}

As usual for goal-oriented interaction, the operator of an UVS is engaged in two activities: achievement of the mission and interaction with the OSS. As stated by Clark [6,7]:

"Dialogues, therefore, divide into two planes of activity. On one plane, people create dialogue in service of the basic joint activities they are engaged inmaking dinner, dealing with the emergency, operating the ship. On a second plane, they manage the dialogue itself-deciding who speaks when, establishing that an utterance has been understood, etc. These two planes are not independent; for problems in the dialogue may have their source in the joint activity the dialogue is in service of, and vice versa. Still, in this view, basic joint activities are primary, and dialogue is created to manage them." 
Interaction is defined by the dialog partner's goals to understand each other, in other words to reach a certain degree of intelligibility, sufficient for the current purpose. That means that:

- Perfect understanding is not required. The level of understanding required is directed by the basic activity (i.e. the mission) and the context (e.g. time pressure);

- The attention of the operator (and the associated workload) is split between the two activities.

As we consider that interaction is subordinated to mission achievement and that the operator has finite cognitive resources, interaction complexity should vary depending on the complexity involved by the mission [1]. Indeed, the collaborative effort for a basic activity (i.e. not subordinated) has to be optimized, whereas the collaborative effort for a subordinated activity has to be minimized [8]. Such a behavior is rational (i.e. coherent) at both the collaborative and individual levels [9].

\section{Load adaptation}

Collaborative models of interaction have already been used for the design of OSSs, for example in the WITAS [10] and GeoDialogue [11] projects. The model of collaboration that we propose to use and have outlined in section 2.1 has two main characteristics: (1) the interpretation process is simple and therefore allows for realistic implementation; (2) it supports a wide range of methods for generation and interpretation. As we will see in the following subsections, the OSS can adjust its cooperative attitude toward the operator by choosing among different strategies for handling understanding of communicative acts, as well as for generation and interpretation of communicative acts.

\subsection{Understanding and Non-understanding}

In all collaborative models of interaction, the reaction to the understanding of a communicative act is the same: a positive feedback. These feedbacks range from a simple "OK" to a comprehensive recast of the act (e.g. "OK. Sending UV2 to building B213.") ${ }^{3}$, but from a collaborative point of view, they have the same value.

Concerning non-understandings, several strategies are available, that we illustrate here in decreasing order of collaborative effort on the part of the OSS:

- Proposing a refinement or clarification to the operator (disambiguation) e.g. "Do you mean the building north of the airport?";

- Requesting a refinement or clarification to the operator (disambiguation) e.g. "Which building?";

- Asking for a recasting of the whole communicative act e.g. "Please rephrase.";

\footnotetext{
${ }^{3}$ Again, this example uses natural language for simplicity, but the OSS could very well recast such a communicative act graphically by highlighting UV2 on the display and showing its route toward building $\mathrm{B} 123$.
} 
Coppin, G., Legras, F. and Saget, S.

- $\quad$ Postponing or giving up, because something more urgent is coming e.g. "Hold on... Intruder detected at XY".

The more collaborative effort is put in the non-understanding management by the OSS the less effort is needed from the operator i.e. the operator only needs to answer by "Yes" (or "No") to the question "Do you mean the building north of the airport?" whereas he or she has to recompose his or her request if the OSS replies "Please rephrase." Thus, the management of non-understandings constitutes the first degree of freedom in setting the cooperative attitude of the OSS.

\subsection{Generation and Interpretation}

Similarly, there exist many different strategies with varying levels of complexity for generating and interpreting communicative acts. Our model allows the use of many different strategies e.g.

- Basing interpretation solely on keywords recognition (most basic form of interaction);

- Selfish attitude: considering solely one's own beliefs i.e. not taking into account what the operator knows or is supposed to know. With this strategy, one does not take into account what the other knows, has perceived or how he or she refers to particular objects e.g. if the OSS uses only its own terminology about mission objects for generating of interpreting communicative acts;

- Cooperative attitude: considering solely the other's beliefs or knowledge e.g. if the OSS adopted a selfish attitude, the operator would have to adopt a cooperative one in order to interact;

- Mutual awareness: considering the part of the situational context with is accessible by oneself and by the other e.g. if the OSS uses its own terminology only if the operator has shown sign that he or she understands it;

- Perspective taking on addressee's point of view on mutual awareness;

- Higher levels of consideration of each other's mutual beliefs are possible, but are rarely deployed.

These strategies are listed in order of ascending complexity [12]. Complexity concerns Human beings, who tend to rely on the simplest sufficient strategy for the current purpose, but concerns also the OSS if these strategies are to be implemented. The choice of a strategy for generation and interpretation constitutes the second degree of freedom in setting the cooperative attitude of the OSS.

\subsection{Rationale for Adjusting the Cooperative Attitude of the OSS}

One can define the cooperative attitude of the OSS as its level of contribution to interaction at a given moment, expressed by the choices of strategies for (1) nonunderstanding management and (2) generation and interpretation. A high level of cooperative attitude on the part of the OSS will require less effort from the operator in order to interact with the OSS, thereby allowing him or her to concentrate on the mission. Therefore, it would seem logical to set the OSS at the maximum level of 
cooperative attitude throughout the whole mission. ${ }^{4}$ On the contrary, we argue that it should be beneficial to set the OSS to a lower level of cooperation attitude in some circumstances.

A low level of cooperative attitude on the part of the OSS will force the operator to put more effort in the interaction process. Such an effort will notably lead to:

- Maintaining the operator's situational awareness (SA) i.e. it is easier to lose track of what is happening if all the operator has to do is answering by "Yes" or "No" to the requests of the OSS, particularly during low stress phases of the mission;

- Improving the operator's feeling to be part of a team (working conjointly) with the OSS;

- Constructing and maintaining a common language. Therefore enabling the use of "cooperative" or "mutual awareness" strategies (see section 3.2) later on e.g. by using the "selfish" strategy at one point, the OSS will force the operator to learn its terminology, which will allow for more effective interaction later;

- Developing more accurate model of each other's capabilities by using different interaction possibilities.

Of course, during high-stress, high workload phases of the mission, the OSS should bear the brunt of the interaction workload, therefore relieving the operator. This balancing effect will be all the more pregnant that the operator has had the opportunity to interact at different levels with the OSS.

\section{$4 \quad$ Mutual Modeling}

\subsection{System predictability and mutual modeling}

Being solely focused on the workload assessment may lead to some limitations in setting an adequate mode of man-machine cooperation. Therefore we expect an adequate interaction manager to include or rely on a model of cooperation between the operator and the system.

We consider here the concept of cooperation in the sense of Klein et al.'s approach [13] involving the notions of basic compact, common ground, predictability and directibility. We will not address the basic compact (that represents the underlying agreement of working as a team and of following a cooperative behavior) and the common ground (that we have proposed to enrich in our approach as described here below). Predictability and directibility are on the contrary central in the approach. According to Klein et al., predictability means that the operator is able to anticipate the future behavior and strategies of the system - including interaction strategies - so that (s)he can better synchronize and coordinate with it. Still according to these

\footnotetext{
${ }^{4}$ We will not consider computational power in the scope of this paper, even though it could indeed happen that some interaction strategies are too cost intensive in some circumstances.
} 
Coppin, G., Legras, F. and Saget, S.

authors, directibility means that the operator is able to "guide" the system towards a desired behavior.

According to this approach this means that both operator and system should have a model of each other. This mutual modeling can be used for a better cross-estimation of mutual performances and for feeding an optimized allocation mechanism functioning at meta level. But it also opens to the setting of a different kind of relationship between the operator and the system based on trust.

\subsection{Trust}

Classical models of trust are trying to associate the concepts of workload, trust and global performances. Lee's model [14], for instance, proposes to compute a dynamical level of trust through a first order autoregressive equation as follows:

$\operatorname{Trust}(\mathrm{t})=\mathrm{a}_{1} \operatorname{Trust}(\mathrm{t}-1)-\mathrm{a}_{2} \operatorname{Fault}(\mathrm{t})+\mathrm{a}_{3} \operatorname{Fault}(\mathrm{t}-1)+\mathrm{a}_{4} \operatorname{perf}(\mathrm{t})-\mathrm{a}_{5} \operatorname{perf}(\mathrm{t}-1)$

where perf is the system's (i.e. operator + machine) performance and fault represents a fractional variation of the control system in regard with the reference values.

Still according to Lee et al. [i], one can derive from this equation a percentage of work allocation to the automation, defined through:

work_auto $(\mathrm{t})=$ work_auto $(\mathrm{t}-1)+\mathrm{b}_{1}(\operatorname{Trust}(\mathrm{t})-\mathrm{Sc}(\mathrm{t}))+\mathrm{b} \operatorname{Indiv}+\mathrm{e}$

where work_auto(t) is the percentage of work allocated to the machine at time $t, \operatorname{Sc}(t)$ is the level of self-confidence, Indiv is a constant individual bias depending on the operator and e a random noise.

Even if possibly adapted to our context of multi vehicle control, this kind of model obviously ignores the effect of adequate (or inadequate) interaction between the operator and the system on trust and - possibly mutual - reliance.

Based on our approach of adaptive interaction management, we can propose to enhance the classical approaches with new indicators, especially such as the level of understanding that may have been reached and, as a correlate, the relevance of the communication strategy of the automata according to the context and the operator workload.

Thus taking into account interaction strategies and modes allow us to go beyond classical performance (observation of behavior) analysis and to include complementary aspects of trust such as process (understanding of causal mechanisms) and purpose (intend of use) aspects.

\section{Conclusion}

This paper aims at emphasizing the role and interest of interaction management in man-machine cooperation and adaptive authority sharing. Dynamical management of 
interaction may not only have direct impact on the global workload of the operator while impacting the interaction-related workload, but also have a direct impact on the operator's trust in the system. Increasing the level of trust in the system should have at least indirectly - a positive impact on the way the operator uses the automation and should consequently lead to performance enhancement.

\section{References}

1. Mouloua, M., Gilson, R., Kring, J., Hancock, P.A.: Workload, situation awareness, and teaming issues for UAV/UCAV operations. Proceedings of the Human Factors and Ergonomics Society, Vol. 45, pp. 162--165. (2001)

2. C. Johnson. Inverting the control ratio: Human control of large, autonomous teams. In Proceedings of AAMAS'03 Workshop on Humans and Multi-Agent Systems. (2003)

3. F. Legras and G. Coppin. Autonomy spectrum for a multiple UAVs system. In COGIS'07 COgnitive systems with Interactive Sensors. (2007)

4. Grice, H. P. (1975). Logic and conversation, Syntax and Semantics, Speech Acts, Vol. 3, pp. $43-58$.

5. Searle, J. R. (1969). Speech acts: an essay in philosophy of language. Cambridge, UK: Cambridge University Press.

6. Clark, H.H. (1996). Using language. Cambridge, UK: Cambridge University Press.

7. Bangerter, A., and Clark, H. H., (2003). Navigating joint projects with dialogue. Cognitive Science, Vol. 27, pp. 195-225.

8. Cherubini, M., van der Pol, J. (2005). Grounding is not shared understanding: Distinguishing grounding at an utterance and knowledge level. CONTEXT'05.

9. Saget, S., Guyomard, M. (2006). Goal-oriented dialog as a subordinated activity involving collective acceptance. Proceedings of Brandial'06, University of Potsdam, Germany, pp. 131-138.

10. Lemon, O., Gruenstein, A., Cavedon, L., and Peters, S. (2002). Collaborative dialogue for controlling autonomous systems. In Proccedings of the AAAI Fall Symposium.

11. Cai, G., Wang, H. and MacEachren, A. (2003). Communicating Vague Spatial Concepts in Human-GIS Interactions: A Collaborative Dialogue Approach. Proceedings of the Conference on Spatial Information Theory 2003, pp. 304-319 (2002)

12. Bard, E. G. , Anderson, A. H. , Chen, Y., Nicholson, H., and Havard, C.. Let's you do that: Enquiries into the cognitive burdens of dialogue. In Proceedings of DIALOR'05, 2005. Designing for appropriate reliance. Human Factors, 46, pp. 50--80.

13. Klein, G., Feltovich, P.J., Bradshaw, J.M., \& Woods, D. D., Common ground and coordination in joint activity. In W.R. Rouse \& K.B. Boff (Eds.), Organizational simulation. New York: Wiley, 2005

14. Lee, J.D., and Moray, N., trust, self-confidence, and operator's adaptation to automation, International Journal of Human-Computer Studies, 40, 153-184, 1994 